\title{
Glutathione S-Transferase Theta 1 / Mu 1 Null Genotype and Risk of Development of Actinic Keratosis in Pakistani Population
}

\author{
Muhammad Imran Bajwa, Amena Rahim, Muhammad Afzal and Amna Mahmood \\ Islamic International Medical College, Rawalpindi, Pakistan
}

\begin{abstract}
Objective: To assess the frequency and association of Glutathione S-Transferase Theta 1 and Glutathione S-Transferase Mu 1 null genotypes in development of actinic keratosis (AK) in a group of Pakistani population.

Study Design: Case-control analytical study.

Place and Duration of Study: Department of Biochemistry, Islamic International Medical College, Rawalpindi in collaboration with Department of Dermatology, Railway Hospital and Rural Health Center, District Health Office, Rawalpindi from September 2018 to September 2019.

Methodology: A total of 86 participants were included in this study with 27 biopsy proven cases of AK and 59 matched controls. Blood samples were collected after obtaining written informed consent; and DNA was extracted by Chelex ${ }^{\mathrm{TM}}$ method. Multiplex PCR (M-PCR) was done to find respective allelic frequencies of GSTM1 and GSTT1 genes in both cases and controls.

Results: Mean age of participants in cases and controls was $62.93 \pm 10.29$ years and was $61.42 \pm 9.96$ years, respectively. There were 18 males (66.7\%) and 9 females (33.3\%); and 43 males (72.9\%) and 16 females $(27.1 \%)$ in cases and controls, respectively. There was a significant association of GSTT1 null genotype with AK (OR: $2.72,95 \% \mathrm{Cl}: 1.05-7.05, \mathrm{p}=0.037$ ). There was a positive correlation between GSTT1 null genotype and AK ( $r=0.225, p=0.037)$.

Conclusion: GSTT1 null genotype has a significant association for AK development in the studied Pakistani population.
\end{abstract}

Key Words: Actinic keratosis, Glutathione S-Transferase Mu 1, Glutathione S-Transferase Theta 1, Polymerase chain reaction, Squamous cell carcinoma.

How to cite this article: Bajwa MI, Rahim A, Afzal M, Mahmood A. Glutathione S-Transferase Theta 1 / Mu 1 Null Genotype and Risk of Development of Actinic Keratosis in Pakistani Population. J Coll Physicians Surg Pak 2020; 30(06):574-578 https://doi.org/10.29271/jcpsp.2020.06.574.

\section{INTRODUCTION}

Skin cancer is the most common human malignancy in the world, affecting people from all ethnicities and geographical regions. ${ }^{1}$ There are no current studies available showing incidence and prevalence of actinic keratosis in Pakistan, except a study which found frequency of AK lesions to be $7 \%$ amid the patients presenting with various cutaneous malignancies. ${ }^{2}$ Worldwide epidemiological data show a higher prevalence of actinic keratosis (AK), which is higher in those regions where population is exposed to more UV radiation like Europe and America. ${ }^{3}$

An Iranian study on geriatric population aged 60 years and above, found AK lesions to be most common precancerous lesion in these patients.

Correspondence to: Dr. Muhammad Imran Bajwa, Islamic International Medical College, 274, Old Supreme Court Building. Peshawar Road, Rawalpindi, Pakistan

E-mail:m_imranbajwa@yahoo.com

Received: October 11, 2019; Revised: June 04, 2020;

Accepted: July 02, 2020

DOI: https://doi.org/10.29271/jcpsp.2020.06.574
Fitz Patrick's photo type (FST) classification, which is based on one's ability to tan or burn, is commonly used for assessing skin cancer risk and skin color classification. ${ }^{4}$ FST grades skin color from type 1 to 6 where type 1 to 3 are considered lighter skin photo types and type 4 to type 6 are considered darker skin photo types. ${ }^{5}$ AK lesions occur most commonly in type 2 and type 3 skin photo types, which together account for $80 \%$ to $90 \%$ of all AK cases. ${ }^{6}$

Actinic keratosis is an intraepithelial atypical proliferation of keratinocytes. The lesions of AK are characterised by rough, scaly spots, skin-colored, reddish or reddish-brown, nodules or plaques. ${ }^{7}$ AK may lead to malignant transformation like squamous cell carcinoma (SCC). Male gender, old age, light colored skin (Fitz Patrick's skin types 1 to 3), severe baldness, skin wrinkling, and relatively high tendency for sunburn are associated with extensive UV damage. ${ }^{8}$ Many squamous cell carcinomas arise from a pre-existing AK. ${ }^{9}$ Therefore, DNA damage due to sun exposure and UV induced formation of reactive oxygen species (ROS) are initial events that lead to most common histologic and clinical manifestations of chronic sun induced damage to the skin. ${ }^{10}$ 
Table I: Primer sequences.

\begin{tabular}{|c|c|c|c|}
\hline Primer & Locus & Product size in $\mathrm{BP}$ & Primer sequences, $5^{\prime}$ to $3^{\prime}$ \\
\hline GSTM1 (F) & \multirow{2}{*}{ GSTM1 } & \multirow{2}{*}{215} & GAACTCCCTGAAAAGCTAAAGC \\
\hline GSTM1 (R) & & & GTTGGGCTCAAATATACGGTGG \\
\hline GSTT1 (F) & \multirow{2}{*}{ GSTT1 } & \multirow{2}{*}{480} & TTCСTTACTGGTCCTCACATCTC \\
\hline GSTT1 (R) & & & TCACCGGATCATGGCCAGCA \\
\hline$\beta$-globin (F) & \multirow{2}{*}{$\beta$-globin } & \multirow{2}{*}{286} & САACTTCATCCACGTTCACC \\
\hline$\beta$-globin (R) & & & GAAGAGCCAAGGACAGGTAC \\
\hline
\end{tabular}

Table II: Association of GSTT1 and GSTM1 genotypes in AK patients and control group.

\begin{tabular}{|c|c|c|c|c|c|}
\hline $\begin{array}{l}\text { Total } \\
N=86\end{array}$ & $\begin{array}{c}\text { Cases } \\
\mathrm{N}=\mathbf{2 7} \\
\mathrm{n}=(\%)\end{array}$ & $\begin{array}{c}\text { Controls } \\
N=59 \\
N=(\%)\end{array}$ & $\begin{array}{c}\text { OR } \\
(95 \% \mathrm{Cl})\end{array}$ & $\begin{array}{c}\text { RR } \\
(95 \% \mathrm{Cl})\end{array}$ & p-value \\
\hline \multicolumn{6}{|c|}{ GSTT1 Genotype } \\
\hline Wild type & $9(33.3)$ & $34(57.6)$ & \multirow{2}{*}{$2.72(1.05-7.05)$} & $0.58(0.33-1.03)$ & \multirow{2}{*}{$0.037 *$} \\
\hline Null type & $18(66.7)$ & $25(42.4)$ & & $1.57(1.06-2.35)$ & \\
\hline \multicolumn{6}{|c|}{ GSTM1 Genotype } \\
\hline Wild type & $16(59.3)$ & $35(59.3)$ & \multirow{2}{*}{$1.00(0.39-2.53)$} & $0.99(0.69-1.46)$ & \multirow{2}{*}{0.996} \\
\hline Null type & $11(40.7)$ & $24(40.7)$ & & $1.00(0.58-1.74)$ & \\
\hline
\end{tabular}

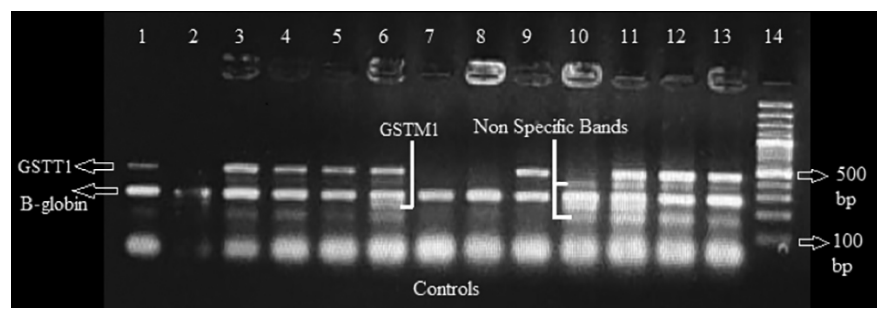

Figure 1: Amplified GSTT1, GSTM1 bands separated on electrophoresis. GSTT1 = Glutathione S-Transferase Theta 1; GSTM1 = Glutathione S-Transferase Mu 1; B-globin = Beta globin.

GSTM1 at 215 bp is present in $2^{\text {nd }}, 6^{\text {th }}, 10^{\text {th }}$ and $11^{\text {th }}$ sample.

GSTT1 at 480 bp is present in $1^{\text {st }}, 3^{\text {rd }}, 4^{\text {th }}, 5^{\text {th }} 6^{\text {th }}, 9^{\text {th }}, 11^{\text {th }}, 12^{\text {th }}$ and $13^{\text {th }}$ sample.

$\beta$ - Globin at 286 bp is present in all samples as an internal control.

Gene Ruler TM 100 bp ladder in $14^{\text {th }}$ well.

Glutathione S-Transferases (GSTs) are found to play a vital role in cell's defence against noxious compounds, ROS and confers resistance to drugs by reducing them to less toxic substances by glutathione conjugation reactions. ${ }^{11}$ GSTs also transform the carcinogenic compounds either environmental or generated within cell to their detoxified form. GSTs are believed to function in xenobiotic/drug detoxification reactions in body once they have undergone oxidation, hydrolysis and reduction. ${ }^{12}$ Two loci in particular, GSTM1 and GSTT1, have received most of the attention among these GST classes because GSTM1 and GSTT1 homozygous deletions are found to be associated with a loss of function mutation (null mutation/genotype) in these genes. ${ }^{13}$ GSTM1/T1 null genotypes are a significant risk factor for sunburn susceptibility; and as mentioned above, cumulative sun exposure including UV rays is an important risk factor for AK development. ${ }^{14}$
The objective of this study was to assess the frequency and association of Glutathione S-Transferase Theta 1 and Glutathione S-Transferase Mu 1 null genotypes in risk of development of actinic keratosis in a group of Pakistani population.

\section{METHODOLOGY}

The study was done at the Department of Biochemistry, Islamic International Medical College, Rawalpindi in collaboration with Department of Dermatology, Railway Hospital and Rural Health Center, District Health Office, Rawalpindi after approval from the Ethical Review Committee of Islamic International Medical College, from September 2018 to September 2019.

Study subjects included were diagnosed, biopsy proven cases $(n=27)$ of actinic keratosis and healthy matched controls $(n=59)$. Exclusion criteria were malignancy, immunosuppressive agent use like steroid therapy, immunodeficiency syndromes, hormonal abnormalities and treatment with ultra violet $A$ (UVA), ultra violet $B$ (UVB) and Psoralen ultra violet $A$ (PUVA) therapy in this study subjects. Biopsy proven cases, who had any degree of AK lesions, were taken including those who had taken any sort of prior treatment for the disease and had recurrence history, healthy matched controls without AK lesions fulfilling the above described criteria were taken as controls. They aged 45 years and above from all ethnic backgrounds and common skin photo types found in Pakistan. As prevalence and incidence of AK is unknown in Pakistani population, taking into consideration 
the low prevalence of AK in the neighboring countries like China which is $0.52 \%$ yields a very low sample size of 8 by online sample size calculator (Raosoft ${ }^{\mathrm{TM}}$ ). ${ }^{15}$ Therefore, convenient non-probability sampling technique was employed in this study to gather as much samples as possible during the study duration.

Blood samples were collected from study subjects for GSTM1 and GSTT1 genotype analysis. DNA was extracted from blood samples by Chelex ${ }^{\mathrm{TM}}$ method. ${ }^{16}$ Extracted DNA was then stored at -80 degrees Celsius till further analysis in labelled Eppendorf tubes. Reverse and forward primers, each of GSTM1, GSTT1 and $\beta$-globin, were used for amplification of respective genes where $\beta$-globin gene was taken as internal control. Primer sequences used are given in Table I.

The PCR reaction was performed by Multiplex PCR technique in separate tubes in which each tube contained forward primer and reverse primer specific to GSTM1 and GSTT1 including primers for $\beta$-Globin genes. The final total volume for each PCR reaction was $32 \mu \mathrm{L}$ which includes $6 \mu \mathrm{l} \mathrm{PCR}$ water, $16 \mu \mathrm{l} 2 \mathrm{x}$ thermo scientific ${ }^{\mathrm{TM}}$ master mix containing thermus aquaticus (Taq) polymerase, dNTP's and $\mathrm{MgCl}_{2}$ as per manufacturer's specifications, $1 \mu$ of each primer which added to total $6 \mu \mathrm{l}$ from 6 primers and $4 \mu$ of DNA from sample to be analysed.

The PCR amplification begun with an initial denaturation at $94^{\circ} \mathrm{C}$ for 7 minutes, followed by 40 amplification cycles which encompassed denaturation at $94^{\circ} \mathrm{C}$ for 50 seconds, annealing at $62^{\circ} \mathrm{C}$ for 45 seconds, and extension at $72^{\circ} \mathrm{C}$ for 52 seconds. The final extension was carried out at $72^{\circ} \mathrm{C}$ for 12 minutes, and cycle was terminated to hold at $4^{\circ} \mathrm{C}$. Reaction mixtures containing amplified genes were subjected to electrophoresis on $2 \%$ agarose gel premixed with $0.5 \mu \mathrm{g} / \mathrm{ml}$ concentration of ethidium bromide in $1 \times$ TBE buffer solution. Electrophoresis was done for 65 minutes with current settings at $700 \mathrm{~mA}$ and voltage setting at $100 \mathrm{~V}$. Amplified bands were visualised by UV320 trans-illumination under UV camera in Gene Box ${ }^{\mathrm{TM}}$ by Gene Sys ${ }^{\mathrm{TM}}$. Gene Ruler ${ }^{\mathrm{TM}} 100 \mathrm{bp}$ (base pair) DNA reference ladder was used as a reference to determine size of amplified bands in base pairs (Figure 1).

Statistical analysis was performed by using IBM ${ }^{\text {"' }}$ SPSS version 21. Demographic and genotype frequencies were determined. Chi-square test was performed to find significance between our study groups and genotypes of interest that are GSTT1 and GSTM1. Odds ratio (OR) was calculated to find odds of absence or presence of GSTT1 and GSTM1 genotypes in development of actinic keratosis. Risk ratios (RR) were calculated to ascertain the risk of developing AK lesions with wild or null alleles of GSTT1 and GSTM1 genotypes. Finally correlation analysis was performed to see the association of these genes in development of actinic keratosis. Ninety- five percent confidence intervals and $p$ value of less than 0.05 was taken as significant in all the statistical analyses.

\section{RESULTS}

There were a total of 27 cases and 59 controls, the age ranged from 47 to 85 years in cases and 45 to 84 years in controls. Mean age of participants in cases and controls was $62.93 \pm 10.29$ years and $61.42 \pm 9.96$ years, respectively. There were 18 males (66.7\%) and 9 females (33.3\%); and 43 males $(72.9 \%)$ and 16 females (27.1\%) among the cases and the controls, respectively. In cases, 3 patients (11.1\%) belonged to skin photo type 3, 15 patients (55.6\%) belonged to skin photo type 4 , and 9 patients (33.3\%) belonged to skin photo type 5 . In controls, 4 patients $(6.8 \%)$ belonged to skin photo type 3,32 patients $(54.2 \%)$ belonged to skin photo type 4 , and 23 patients $(39.0 \%)$ belonged to skin photo type 5 .

GSTT1 null genotype was found to be significantly associated with risk of development of actinic keratosis (OR: 2.72, $95 \% \mathrm{Cl}: 1.05-7.05, \mathrm{p}=0.037$ ). Furthermore, the risk of AK development increased by 1.57 times in absence of GSTT1 genotype or wild allele (RR: $1.57,95 \% \mathrm{Cl}: 1.06-2.35, \mathrm{p}=$ 0.037), Table II. There was a significant positive correlation between GSTT1 null allele and risk of development of actinic keratosis $(r=0.225, p=0.037)$.

\section{DISCUSSION}

Skin cancer by far continues to remain most common human malignancy worldwide with particular high incidence in fair complexioned population and those who were exposed to higher doses of UV rays like people living on altitudes. ${ }^{17}$ Actinic keratosis arises in UV exposed skin due to irreversible DNA damage caused by UV light and is considered as a pre-malignant lesion, which has a higher risk of progression to invasive squamous cell carcinoma. Therefore, diagnosing and devising early and effective treatment plan for actinic keratosis lesions prevention and treatment is paramount. $^{18}$

Human Glutathione S-Transferases (GSTs) comprise of cytosolic and microsomal superfamilies, which are further subdivided into various subfamilies and are involved in second phase of detoxification reactions, which includes conjugation of reduced glutathione to xenobiotics or drugs in human body. ${ }^{19}$ The cytosolic family includes GST $\alpha$, GST $\mu$, GST $\theta$, and GST $\pi$, while other members of family are microsomal. ${ }^{20}$ GSTT1 and GSTM1 are genes which belong to cytosolic superfamily of GSTs and have role in ROS induced damage prevention at cellular and molecular level. As UV rays in addition to causing direct DNA damage also induces ROS generation, the healthy activity of these genes assumes great importance in protecting further damage and pre-malignant changes in cell. ${ }^{21}$

In the current study, there was significant association between absence of GSTT1 allele and increased risk of development of actinic keratosis. There was a positive correlation 
between GSTT1 genotype and AK lesions formation as well. The risk of AK was 1.57 times higher than normal when a subject has GSTT1 null genotype.

This study corresponds with the other studies performed worldwide investigating possible role of these genotypes in etiology and pathogenesis of AK and skin cancer. The findings in current study are similar to the results of an Italian study, which found GSTT1 null allele to be significantly related to the risk of AK development. ${ }^{22}$ A recent study conducted on Iranian population concluded that GSTT1 and GSTM1 null genotypes were associated with risk of developing basal cell carcinoma of skin. ${ }^{23}$ Another study done on southern Italian population including 262 subjects found no association of GSTT1 and GSTM1 null allele with risk of melanoma skin cancer. ${ }^{14}$

This is the first study of its kind in Pakistan showing association of GSTT1/M1 null genotypes with development of actinic keratosis lesions. The study subjects represent the commonest skin photo types present in Pakistan. The study was multicenter employing study participants from different centres in Rawalpindi.

Due to rarity of the disease in question and small duration of study, number of cases was low. It was a case-control study lacking longitudinal follow-up of study subjects. Nationwide studies employing larger sample size and more genetic markers are warranted.

\section{CONCLUSION}

GSTT1 null genotype was found to be significantly associated with risk of development of actinic keratosis. The risk of AK development increases significantly in absence of GSTT1 genotype. There was a significant positive correlation between GSTT1 null allele and risk of development of actinic keratosis.

\section{ETHICAL APPROVAL:}

The study was approved from Ethical Review Committee of Islamic International Medical College, Rawalpindi, Pakistan.

\section{PATIENTS' CONSENT:}

Written informed consents were obtained from study participants.

\section{CONFLICT OF INTEREST:}

Authors declared no conflict of interest.

\section{AUTHORS' CONTRIBUTION:}

MIB: Data collection, drafting of manuscript and statistical analysis.

AR: Critical review of content and study planning,

MA: Laboratory support and PCR optimisation.

AM: Patient counselling and sample collection.

\section{REFERENCES}

1. Esteva A, Kuprel B, Novoa RA, Ko J, Swetter SM, Blau HM, et al.
Dermatologist-level classification of skin cancer with deep neural networks. Nature 2017; 542(7639):115.

2. Paracha MM, Shah AA, Khan MA, Khan SA. Pattern of skin malignancies in patients presenting to dermatology deptartment Hayatabad Medical Complex Peshawar. J Postgraduate Med Inst (Peshawar-Pakistan) 2014; 28(1).

3. Philipp-Dormston WG, Muller K, Novak B, Stromer K, Termeer C, Hammann $U$, et al. Patient-reported health outcomes in patients with non-melanoma skin cancer and actinic keratosis: Results from a large-scale observational study analysing effects of diagnoses and disease progression. J Eur Acad Dermatol Venereol 2018; 32(7): 1138-46.

4. Holm-Schou ASS, Philipsen PA, Wulf HC. Skin cancer phototype: A new classification directly related to skin cancer and based on responses from 2869 individuals. Photodermatol Photoimmunol Photomed 2019; 35(2): 116-23.

5. Alexis AF, Coley MK, Nijhawan RI, Luke JD, Shah SK, Argobi $Y A$, et al. Nonablative fractional laser resurfacing for acne scarring in patients with fitzpatrick skin phototypes IV-VI. Dermatol Surg 2016; 42(3):392-402.

6. Ferrándiz-Pulido C, Lera-Imbuluzqueta M, Ferrándiz C, Plazas-Fernandez M. Prevalence of actinic keratosis in different regions of Spain: The epiqa study. Actas Dermosifiliogr 2018; 109(1):83-6.

7. Stockfleth $E$. The importance of treating the field in actinic keratosis. J Eur Acad Dermatol Venereol 2017; 31(1):8-11.

8. Cramer P, Stockfleth E. Actinic keratosis: Where do we stand and where is the future going to take us? Expert Opin Emerg Drugs 2020; 25(1):49-58.

9. Que SKT, Zwald FO, Schmults CD. Cutaneous squamous cell carcinoma: Incidence, risk factors, diagnosis, and staging. J Am Acad Dermatol 2018; 78(2):237-47.

10. Bilaç C, Şahin MT, Öztürkcan S. Chronic actinic damage of facial skin. Clin Dermatol 2014; 32(6):752-62.

11. Allocati N, Masulli M, Di Ilio C, Federici L. Glutathione transferases: Substrates, inihibitors and pro-drugs in cancer and neurodegenerative diseases. Oncogenesis 2018; 7(1):8.

12. Li S, Xue F, Zheng Y, Yang P, Lin S, Deng $Y$, et al. GSTM1 and GSTT1 null genotype increase the risk of hepatocellular carcinoma: Evidence based on 46 studies. Cancer Cell Int 2019; 19(1):76.

13. Grubisa I, Otasevic P, Vucinic N, Milicic B, Jozic T, Krstic S, et al. Combined GSTM1 and GSTT1 null genotypes are strong risk factors for atherogenesis in a Serbian population. Genet Mol Biol 2018; 41(1):35-40.

14. Guarneri F, Asmundo A, Sapienza D, Borgia F, Papaianni V. Glutathione S-transferase M1/T1 genotype and melanoma in a Southern Italian population: A case-control study. G Ital Dermatol Venereol 2016; 151(2):140-4.

15. Zhao Y, Li C, Wen C, Wei Y, Li R, Wang G, et al. The prevalence of actinic keratosis in patients visiting dermatologists in two hospitals in China. British J Dermatol 2016; 174(5):1005-10.

16. Mohammadi S, Esfahani B, Moghim S, Mirhendi H, Zaniani F, Safaei $H$, et al. Optimal DNA isolation method for detection of nontuberculous mycobacteria by polymerase chain reaction. Adv Biomed Res 2017; 6:133. 
17. Savoye I, Olsen CM, Whiteman DC, Bijon A, Wald L, Dartois $L$, et al. Patterns of ultraviolet radiation exposure and skin cancer risk: The E3N-SunExp study. J Epidemiol 2017; 28(1):22-33.

18. John SM, Trakatelli M, Gehring R, Finlay K, Fionda C, Wittlich $M$, et al. Consensus report: Recognizing non-melanoma skin cancer, including actinic keratosis, as an occupational disease: A call to action. J Eur Acad Dermatol Venereol 2016; 30(3):38-45.

19. Tan HM, Low WY. Rapid birth-death evolution and positive selection in detoxification-type glutathione S-transferases in mammals. PloS One 2018; 13(12):e0209336.

20. Hollman A, Tchounwou P, Huang H-C. The association between gene-environment interactions and diseases involving the human GST superfamily with SNP variants. Int J Environmental Res Public Health 2016; 13(4):379.

21. Sample A, He YY. Mechanisms and prevention of UV-induced melanoma. Photodermatol Photoimmunol Photomed 2018; 34(1):13-24.

22. Guarneri F, Asmundo A, Sapienza D, Gazzola A, Cannavò SP. Polymorphism of glutathione S-transferases M1 and T1: Susceptibility to solar keratoses in an Italian population. Clin Exp Dermatol 2010; 35(7):771-5.

23. Ranjbar PA, Rakhshan A, Mashayekhi F, Majidzadeh $Y$, Hatamnejadian N, Mostafavi SS, et al. Evaluation of common polymorphisms (GTSM1, GSTT1 and GSTP1) in Sglutathione transferase family and susceptibility to basal cell carcinoma $(B C C)$ in Iranian population. Health Biotechnol Biophar 2018; 2(4):40-55. 